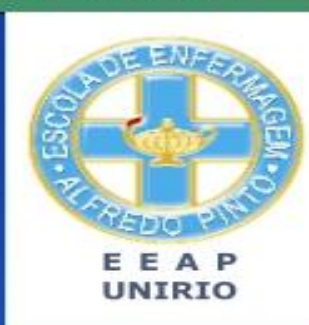

2. Ministério da Educação

\title{
PESQUISA
}

\section{REFLECTIONS ON THE QUALITY OF WORK LIFE OF NURSES IN THE PREHOSPITAL}

REFLEXOS DO TRABALHO NA QUALIDADE DE VIDA DE ENFERMEIROS

REFLEXIONES SOBRE LA CALIDAD DE VIDA LABORAL DE LÃS ENFERMERAS EM EL PREHOSPITALARIO

Cláudia Cristiane Filgueira Martins ${ }^{1}$, Alcivan Nunes Vieira ${ }^{2}$, Viviane Euzebia Pereira Santos ${ }^{3}$

\section{ABSTRACT}

Objective: To describe how nurses working in the SAMU Mossoró-RN, Brazil, realize the consequences of this type of work in their quality of life. Methods: A qualitative descriptive approach, in which semi-structured interview was used to describe the reflections of the work on quality of life of these professionals. The study included six nurses of SAMUMossoró-RN. Results: The subjects related to the confrontation with stressful situations in nature interferes with the quality of life being expressed weariness and discouragement, and do not have time to develop activities that you deem pleasure out of the workplace. Conclusion: The nursing professional must seek activities that you deem as much pleasure and satisfaction in the workplace and outside it to your body and mind do not become victims of negative consequences that living for the job provides. Descriptors: Nursing, Quality of Life, Urgency, Emergency.
\end{abstract}

\section{RESUMO}

Objetivo: Descrever como os enfermeiros que atuam no SAMU-Mossoró-RN, Brasil, percebem os reflexos desse tipo de trabalho em sua qualidade de vida. Métodos: Estudo qualitativo de abordagem descritiva, em que foi utilizada a entrevista semiestruturada a fim de descrever os reflexos do trabalho na qualidade de vida desses profissionais. Participaram do estudo seis enfermeiros do SAMU Mossoró-RN. Resultados: Os participantes do estudo relacionaram que o confronto com situações de natureza estressante interfere na qualidade de vida sendo expresso em cansaço e desmotivação, além de não possuir tempo para o desenvolvimento de atividades que the deem prazer fora do ambiente de trabalho. Conclusão: 0 profissional de enfermagem deve buscar atividades que the deem prazer e satisfação tanto no ambiente de trabalho como fora dele para que o seu corpo e mente não se tornem vítimas das consequências negativas que o viver para o trabalho proporciona. Descritores: Enfermagem, Qualidade de Vida, Urgência, Emergência.

\section{RESUMEN}

Objetivo: Describir cómo lãs enfermeras que trabajan em el SAMU- Mossoró-RN, Brasil, conscientes de lãs consecuencias de este tipo de trabajo en su calidad de vida. Métodos: Un enfoque cualitativo, descriptivo, em el que se utilizó la entrevista semiestructurada para describir las reflexiones de los trabajos sobre La calidad de vida de estos profesionales. El estúdio incluyó a seis enfermeras del SAMU Mossoró-RN. Resultados: Los temas relacionados con el enfrentamiento con situaciones de estrés em La naturaleza interfiere con La calidad de vida que se expresa $\mathrm{El}$ cansancio y el desaliento, y no tienen tiempo para desarrollar lasactividades que consideren elplacer fueradel lugar de trabajo. Conclusión: El profesional de enfermería debe buscar actividades que se consideren placer y satisfacción em el trabajo y fuera de ella a su cuerpo y la mente no se conviertan em víctimas de lãs consecuencias negativas que vivir para el trabajo proporciona. Descriptores: Enfermería, Calidad de Vida, Urgencias, Emergencias.

\footnotetext{
1 Enfermeira. Mestranda do Programa de Pós-Graduação da Faculdade de Enfermagem da Universidade Federal do Rio Grande do Norte. Membro do laboratório de investigação do cuidado, segurança e tecnologia em saúde e Enfermagem. Bolsista CAPES. E-mail: claudiacrisfm@yahoo.com.br. ${ }^{2}$ Enfermeiro, Professor da Faculdade de Enfermagem da Universidade do Estado do Rio Grande do Norte (UERN). Mestre em Cuidados Clínicos em Saúde pela Universidade Estadual do Ceará (UECE). E-mail: alcivan.nunes@yahoo.com.br. ${ }^{3}$ Enfermeira, Professora Doutora, colaboradora do Programa de pós graduação em enfermagem da UFRN, professora adjunta do Departamento de Enfermagem da Universidade Federal do Rio Grande do Norte. Membro do laboratório de investigação do cuidado, segurança e tecnologia em saúde e Enfermagem. E-mail: vivianeepsantos@gmail.com.
} 


\section{INTRODUÇÃO}

O atendimento pré-hospitalar móvel (APHM) tem como finalidade realizar a assistência fora do ambiente hospitalar e no local em que ocorreu o agravo a saúde da vítima. ${ }^{1}$ As ações realizadas podem ser de origem clínica, traumática ou psiquiátrica e são voltadas prioritariamente para a manutenção da vida. Esse atendimento é prestado pelo serviço de atendimento móvel às urgências (SAMU), que foi regulamentado no Brasil pela portaria 2048, em 2002.

A equipe atuante no SAMU é composta por médicos, enfermeiros, técnicos de enfermagem e socorristas, esses profissionais são os primeiros a prestar suporte de vida as vítimas, podendo encontrá-las nas mais inesperadas situações a depender do tipo de agravo que ela sofreu.

Sendo assim, atuar neste ambiente possui riscos intrínsecos. Um desses é o cotidiano em uma unidade de suporte avançado sendo frequentemente caracterizado por pacientes em estado grave, morte, contato com situações inesperadas de acidentes e traumas, trabalho noturno, condições de trabalho insalubre, fatores ergonômicos, além de ser uma rotina permeada basicamente por casos de urgência e emergência. ${ }^{2}$

Diante disto, com a finalidade de conhecer se essa rotina de trabalho exerce influências na qualidade de vida dos enfermeiros que nela atuam, foi elaborada como questão norteadora: "Quais os reflexos do trabalho no APH na qualidade de vida dos enfermeiros que nele atuam?"

A relevância desse estudo concerne no fato de que se conhecendo e entendendo os reflexos do trabalho na vida pessoal e profissional desses trabalhadores da saúde pode-se buscar estratégias de minimização dessas consequências, integrando esse profissional com o que pode oferecer para
Reflections on the quality...

seja possível ter qualidade de vida também no ambiente de trabalho.

Assim, esse estudo teve como objetivo descrever como os enfermeiros que atuam no SAMU em Mossoró-RN, Brasil, percebem os reflexos desse tipo de trabalho em sua qualidade de vida.

\section{METODOLOGIA}

Estudo qualitativo, com abordagem descritiva desenvolvida junto aos enfermeiros do serviço de atendimento móvel às urgências (SAMU) em Mossoró-RN, Brasil.

Os dados foram coletados no período de março a abril de 2010 na sede do SAMU Mossoró$\mathrm{RN}$, após a aprovação do projeto pelo comitê de ética e pesquisa da Universidade do Estado do Rio Grande do norte, obtendo aprovação sob protocolo número: 51.09 .

No total são sete funcionários, dos quais seis aceitaram participar da pesquisa. Todos se enquadraram nos seguintes critérios de inclusão: atuarem no serviço há mais de seis meses; disponibilidade em participar da pesquisa fora do expediente no SAMU; concordar em assinar o TCLE.

Os dados coletados foram gravados em aparelhos de Mp4 e arquivados, depois de transcritos, em banco de dados criado no computador da pesquisadora. Em seguida, os dados foram tratados por meio da análise de conteúdo de Bardin, o que permitiu uma análise sistemática dos dados, permitindo o processo de criação das categorias, classificando as falas dos entrevistados em idéias comuns. ${ }^{3}$

Sendo assim, encontrou-se como categorias: 0 cotidiano do $\mathrm{APH}$ : reflexões sobre a qualidade de vida do enfermeiro e Reflexos do trabalho na vida pessoal dos enfermeiros. 


\section{RESULTADOS E DISCUSSÃO DOS DADOS}

Dos profissionais que aceitaram participar da pesquisa foram dois homens e quatro mulheres. Nesta realidade, podemos traçar o seguinte perfil dos entrevistados: todos tinham mais de quinze anos de formados, três entrevistados possuíam dois vínculos empregatícios, um possuía três e apenas um possuía somente um vínculo.

\section{O cotidiano do APH: Reflexões sobre a qualidade de vida do enfermeiro}

A equipe que atua no SAMU tem o contato direto com situações de urgência e emergências e essas são permeadas por condições complexas devido às características inerentes ao ambiente de atuação. ${ }^{4}$ Esse ambiente é permeado por condições adversas, afinal o atendimento a vítima pode ser realizado em via pública ou em domicilio, sob intempereis climáticos como a presença de chuva, sol e vento, e ainda com a presença dos transeuntes e leigos que, por vezes, prestam um atendimento inicial errado.

0 resultado disso é um cotidiano repleto de situações delicadas e inesperadas, além do próprio contato com a urgência/emergência, o que gera, nesse profissional, uma postura de atenção constante no momento do turno de trabalho, cansaço e estresse. ${ }^{5}$

Essa rotina acaba trazendo consequências diretas à qualidade de vida desses trabalhadores. 0 termo qualidade de vida é relativamente novo e faz referência a um conceito subjetivo dos aspectos da vida pessoal. Ou seja, se remete aquilo que o individuo relata como situações que the deem prazer em fazer.

Os entrevistados, deste estudo, relacionaram a qualidade de vida com o tempo com a família, tempo livre para realização de atividade de lazer que the proporcionem prazer individual e tempo para realização de atividades
Reflections on the quality...

de aprimoramento profissional. Como podemos ver no relato:
Alguns momentos a gente gostaria de estar com a família, de estar em um passeio, em um congresso, em outra atividade profissional de aprendizagem e não nos dá oportunidade pela carga de trabalho que se torna longa para gente. (E2)

Percebo certas reclamações de filho, esposo, perguntando se eu não vou mais voltar. (E6)

Esses participantes retratam a qualidade de vida como uma percepção subjetiva e individual, em conformidade com a literatura pesquisada. Afinal, a qualidade de vida está relacionada ao funcionamento físico, mental, social e ao desempenho de papéis e, inclui ainda habilidades de satisfação com a vida. ${ }^{6}$

No ambiente pré-hospitalar o enfermeiro entra em contato constante com situações de emergência o que acarreta um estresse psicológico e físico intenso, devido à carga emocional e a exigência física de cada situação específica, podendo acarretar a esses profissionais consequências para sua saúde, como pressão elevada, enxaquecas e ritmo de sono alterado.

Além disso, há que se considerar que esses profissionais, em sua maioria, não possuem um só vínculo empregatício devido ao baixo piso salarial da categoria. E ainda, são de maioria feminina tendo que exercer rotina de trabalho dupla e até mesmo tripla conciliando afazeres domésticos com o trabalho em um ambiente gerador em potencial de estresse. Isso também foi relatado pelos entrevistados, como expresso a seguir:

A qualidade de vida interfere demais, porque a gente não é máquina[...] Se nós tivéssemos um trabalho adequado e uma remuneração descente nós não teríamos necessidade de procurar outro vínculo. (E4)

Esse envolvimento exclusivo com 0 ambiente de trabalho faz com que esses profissionais tenham uma redução do autocuidado 
Martins CCF, Vieira AN, Santos VEP.

e das atividades que lhes proporcionam prazer, potencializando o contato exclusivo com o trabalho e com situações que possam lhe desgastar emocionalmente. ${ }^{7}$

Uma pesquisa investigou as interferências negativas que as longas jornadas podem causar aos diversos aspectos da vida dentro e fora do ambiente de trabalho. ${ }^{8}$ Foram elencados como fatores: redução de tempo para o sono, sintomas de fadiga, de estresse, dor e vários tipos de disfunções físicas ou psicológicas.

Os entrevistados desse estudo não mencionaram sintomas diretos ao seu organismo. No entanto relataram que o fato da longa jornada de emprego é refletido em cansaço mental, falta de tempo para uma atividade física ou para uma alimentação adequada. Além disso, foi relatado que muitas vezes a saída de um plantão para outro é como uma obrigação.

Cabe ressaltar que um profissional que se vê nessa situação de aumento de jornada de trabalho tem sua qualidade de vida inteiramente prejudicada, afinal as atividades que the dão prazer ficam dependentes do seu trabalho. E apesar do trabalho ser considerado fonte de prazer quando o trabalhador se torna prisioneiro do seu trabalho trará sofrimento e danos à saúde e qualidade de vida a esse.

\section{Reflexos do trabalho na vida pessoal dos enfermeiros}

$\mathrm{Na}$ realidade do APH todos os profissionais necessitam agilidade de pensamentos e atitudes, além de uma equipe eficiente e integrada no momento da intervenção, realizando um atendimento rápido e eficaz para a manutenção da vida da vítima.

Desta feita, pode ser considerado um ambiente de trabalho que pode proporcionar sentimentos diversos aos seus trabalhadores. Sendo traduzido em sentimentos positivos, de triunfo ao salvar vidas, ou de frustração ao não conseguir salva-las. ${ }^{10}$ Podem ser consideradas R. pesq.: cuid. fundam. online 2012. out./dez. 4(4):2966-71
ISSN 2175-5361

Reflections on the quality...

como situações positivas pelos enfermeiros: atendimentos em que os profissionais conseguem resgatar a vítima com sucesso, estabilizam e realizam o transporte até o hospital de referência, ou ainda situações de reconhecimento e satisfação por parte da população em ter realizado um atendimento adequado e com êxito final. ${ }^{8}$

Esse tipo de prazer que o APH proporciona foi relatado pelos entrevistados quando questionados sobre os reflexos na vida pessoal em relação ao trabalho, como pode ser percebido na seguinte fala:

Eu percebo, agora é positivo. Sinto o reflexo de ter discernimento de eu agir em certas situações de emergência estando estressada. (E2)

Nesse caso, o aspecto positivo relatado é com relação ao prazer que essa atuação oferece, ou seja, fazer o que tem que ser feito mesmo em condições que the exijam um maior nível de atenção e rodeado por pressões do ambiente em salvar a vida da vítima.

No entanto, a maioria dos entrevistados mencionou que sente reflexos negativos na vida pessoal com relação ao desempenho de atuação. A literatura traz que dentre esses a falta de comunicação entre os membros da equipe, situações em que envolva atendimento com crianças, riscos da própria cena do acidente, como presença de arma de fogo ou arma branca, dentre outros.

Tudo isso ocorrendo no próprio ambiente de trabalho pode desestabilizar a atuação dos profissionais acarretando consequências negativas a sua qualidade de vida no trabalho. Porém, o que foi mencionado pelos entrevistados foram as situações e cenas em que é desenvolvido o trabalho. Como pode ser visto nas falas:

Eu acho que só o fato de você trabalhar com agente de natureza estressora não tem como você não levar isso para sua vida pessoal, não tem como você em uma reunião de amigos, em um aniversário de amigo do filho você acaba lembrando de um 
dia aconteceu de uma moto bater em um carro e atingiu uma criança, não tem como você não relacionar.(E4)

Há momentos em que fico pensando, mexe muito na minha vida. Quando é uma morte por agressão [...]toda morte trás transtorno realmente. 0 maior choque é de um jovem por acidente ou agressão. (E1)

Confrontando esses relatos com a literatura percebe-se que o profissional de enfermagem tem que suportar o desgaste físico e psíquico do trabalho com a dor e o sofrimento, a cobrança de responsabilidades se refletindo em insatisfação nas atividades laborais e passando a afetar diretamente os trabalhadores de enfermagem e sua qualidade de vida. ${ }^{12-13}$

O confronto com essas situações acarretam ao ser humano vários danos, afinal a convivência com tensões, com condições negativas, levando ao estresse profissional e, consequentemente, a insatisfação profissional, podendo provocar em sua vida pessoal depressão, perda de interesse e desmotivação. ${ }^{13}$

Outro ponto destacado pelos entrevistados relaciona a qualidade de vida com o tempo de serviço. Foi relatado que o contato com essas situações se acumulam com o decorrer do tempo desempenhado a tal função.

O que eu sou agora não é igual de como eu me formei, me sinto cansada, tensa, já não venho mais para o trabalho com aquele pique de antes. (E4)

Percebe-se com isso, que à medida que o tempo de serviço é acumulado por esses profissionais, eles se sentem cada vez mais cansados em presenciar e conviver com um cotidiano de sofrimento alheio e morte, e isso acaba sendo trazido a sua qualidade de vida, sendo como reflexos maiores a desmotivação em realizar esse tipo de trabalho.

\section{CONSIDERAÇÕES FINAIS}

Os entrevistados desse estudo expressaram como qualidade de vida o tempo com a família, tempo para realização de atividade de lazer que lhe proporcionem prazer individual e tempo para realização de atividades de aprimoramento profissional. E consideraram que a ausência de disso é prejudicial para a melhoria de sua vida pessoal refletindo no desempenho profissional.

Dessa maneira, um profissional que fica restrito ao trabalho, reduzindo seu autocuidado e - lazer pode potencializar situações que the desgastam emocionalmente interferindo diretamente em sua qualidade de vida. Isso acaba por ser traduzido em sintomas psicológicos que em sua maioria são somatizados pelo organismo em doenças crônicas.

Sendo assim, o estudo contribuiu para que esses profissionais pudessem refletir sobre a importância do cuidar de si dentro do ambiente de trabalho. Bem como, a necessidade que este setor possui de realizar atividades que envolva os profissionais e a qualidade de vida desses no ambiente de trabalho.

Vale salientar que este estudo foi realizado com uma população de sete enfermeiros do SAMU-Mossoró, constituindo-se uma realidade única vivenciada. Podendo apresentar aproximações ou distanciamentos de outras realidades, com isso reforça-se a necessidade de novos estudos que possam retratar essa temática.

\section{REFERÊNCIAS}

1. Ministério da Saúde (BR). Secretaria de Atenção à Saúde. Política Nacional de Atenção às urgências. Ministério da Saúde, Secretária de Atenção à Saúde - Brasília (DF); 2004. Disponível em: 
Martins CCF, Vieira AN, Santos VEP.

http://portal.saude.gov.br/portal/arquivos/pd f/Politica\%20Nacional.pdf.

2. Santos JM, Oliveira EB, Moreira AC. Estresse, fator de risco para a saúde do enfermeiro em centro de terapia intensiva. Revenferm UERJ [periódico de internet] 2006 out-dez [acesso em 13 dez. 2011]; 14(4):580-5. Disponível em: http://www.facenf.uerj.br/v14n4/v14n4a14.p df.

3. Bardin L. Análise de Conteúdo. $3^{\circ}$ ed. Portugal: edições 70; 2004.

4. Baggio MA, Callegaro GD, Erdmann AL. Compreendendo as dimensões do cuidado em uma unidade de emergência hospitalar. RevBrasEnferm [periódico de internet] 2009 mai-jun [acesso em 13 dez. 2011]; 62(3): 3816. Disponível em: http://www.scielo.br/pdf/reben/v61n5/a04v6 1n5.pdf.

5. Batista KM, Bianchi ERF. Estresse do enfermeiro em uma unidade de emergência. Rev Latino-am Enfermagem [periódico de internet] 2006 jul-ago [acesso em 13 dez. 2011]; 14(4): 534-9. Disponível em: http://www.scielo.br/pdf/rlae/v14n4/v14n4a 10.pdf.

6. Paiva L. A qualidade de vida e a experiência do trauma para vítima e seus familiares [dissertação]. Ribeirão Preto (SP): Escola de Enfermagem de Ribeirão Preto, Universidade de São Paulo; 2009.

7. Dias LG, Nogueira MM, Dutra GO, Souza BM, Ávila LC. Caracterização e formas de enfrentamento do estresse no profissional de enfermagem de atendimento pré-hospitalar. R. Pesq.: cuid. Fundam [periódico de internet] 2011 jan-mar [acesso em 13 dez. 2011]; 3(2): 1943-58. Disponível em: http://www.seer.unirio.br/index.php/cuidado fundamental/article/view/1047/pdf_355.

8. RomanziniEM, Bock LF. Concepções e sentimentos de enfermeiros que atuam no
ISSN 2175-5361

Reflections on the quality...

atendimento pré-hospitalar sobre a prática e a formação. Rev Latino-am Enfermagem [periódico de internet] 2010 mar-abr [acesso em 05 dez. 2011]; 18(2):8 telas. Disponível em:

http://www.scielo.br/pdf/rlae/v18n2/pt_15.p df.

9. Dejours C. A loucura do Trabalho: estudo da psicopatologia do trabalho. $5^{\circ}$ ed. São Paulo: Cortez-Oboré; 1992.

10. Deslandes SF. Frágeis deuses: profissionais da emergência entre os danos da violência e a recriação da vida. Rio de Janeiro: Fio Cruz; 2002.

11. Secco IAO. Acidentes e cargas de trabalho dos trabalhadores de enfermagem de um hospital universitário do Norte do Paraná [dissertação]. Ribeirão Preto (SP): Universidade de São Paulo; 2006.

12. Martins MM. Qualidade de vida e capacidade para 0 trabalho dos profissionais em enfermagem no trabalho em turnos [dissertação]. Florianópolis (SC): Universidade Federal de Santa Catarina; 2002.

13. Scorsin LM. Santos MS. Nakamura EK. A qualidade de vida no trabalho da enfermagem e seus reflexos na satisfação pessoal. Uniandrade [periódico de internet]. 2006[acesso em 03 dez. 2011]. Disponível em: http: / /lcms.uniandrade.br/publicador/publica coes/Revistas/enfermagem/artigo013.pdf.

Recebido em: 07/02/2012

Aprovado em: 02/08/2012 